\title{
Spatial Distribution and Bioavailability of Some Essential Trace Elements in Southern Ondo State Nigeria
}

\author{
Wasiu B. Tomori ${ }^{1,2}$, Isiaka A. Amoo ${ }^{1}$, Ademola F. Aiyesanmi ${ }^{1}$, Ernest K. Yanful ${ }^{2} \&$ Petrik Leslie $^{3}$ \\ ${ }^{1}$ Department of Chemistry, Federal University of Technology, Akure, Nigeria \\ ${ }^{2}$ Civil and Environmental Engineering Department, Western University, London Ontario, Canada \\ ${ }^{3}$ Department of Chemistry, Environmental and Nano Science Unit, University of Western Cape, South Africa \\ Correspondence: Wasiu B. Tomori, Department of Chemistry, Federal University of Technology, P.M.B. 704, \\ Akure, Nigeria. Tel: 234-803-671-0443. E-mail: wbtomori@futa.edu.ng
}

Received: May 24, 2015 Accepted: June 22, 2015 Online Published: September 28, 2015

doi:10.5539/ep.v4n4p24 URL: http://dx.doi.org/10.5539/ep.v4n4p24

\begin{abstract}
The total elemental content of soil though may give abundance of element concentration but have been found not to be suitable for prediction of environmental bioavailability and toxicity by scientific community. Surface $(0-30 \mathrm{~cm})$ and subsurface $(60-90 \mathrm{~cm})$ soil profile in the Southern Ondo State Nigeria were investigated for spatial distribution, bioavailability and mobility of some essential trace elements ( $\mathrm{Cu}, \mathrm{Fe}, \mathrm{Mn}, \mathrm{Zn})$. Their spatial distribution were very similar in both surface and subsurface soil environment indicating that similar geochemical factors may be responsible for their distribution. The North was composed of basement complex while the South was largely undifferentiated sedimentary rock. Higher concentrations of $\mathrm{Cu}, \mathrm{Fe}, \mathrm{Mn}$ and $\mathrm{Zn}$ were recorded in the North through the centre of study area to lower concentrations in the South. The spatial concentration of the trace elements may have been influenced by the nature of underlying bedrock type. Cu was potentially bioavailable in both surface and subsurface soil environment considering the fact that $>50 \%$ of its total concentration were in the nonresidual fraction. Other trace elements were not bioavailable because $>60 \%$ of their total concentrations were found in residual fractions. The relative risk assessment code of $\mathrm{Cu}$ (surface; subsurface) indicated progressive risk (MoF1, MoF2, MoF3) from low (2-10; 1-6) through medium (12-30; $10-21)$ to high risk $(25-40 ; 21-35)$ in both surface and subsurface soil environment while Zn (surface) shows similar trend $(1-5 ; 11-21 ; 22-35)$ only in the surface soil environment. Other elements show some level of risk to no risk. There is likelihood that $\mathrm{Cu}$ and/or $\mathrm{Mn}$ may be associated with anthropogenic sources.
\end{abstract}

Keyword: spatial distribution, bioavailability, mobility, trace elements, Nigeria

\section{Introduction}

Soil is a part of the ecosystem and it occupies a basic role for humans, because the survival of man is tied to the maintenance of its productivity (Gruhn et al, 2003). Soil functions as a filtering, buffering, storage, and transformation system; thus it protects against the effects of element pollution (Blum et al., 2006). Soil is effective in these functions only as long as the physical, chemical and its biological activities are preserved. Soil is the main source of trace elements for plants both as micronutrients and as pollutants (Kabata-Pendias \& Mukherjee, 2007). It is also a direct source of these elements to humans due to soil ingestion affected by "pica-soil", geophagia, dust inhalation, and absorption through skin (Bisi-Johnson et al 2010).

It has been assumed that the behavior of elements in soils and in consequence their bioavailability differ as to their origin (Zhang et al, 2002). The element transfer from soil is a very complex process governed by several factors, both natural and affected by humans (Roivainen et al, 2012). Soil processes (Retallack, 2001) and anthropogenic factors (Mirsal, 2008) are the major factors that control the behavior of elements in soil. Several recent reports have indicated that regardless of the forms of the anthropogenic elements, their availability to plants is significantly higher than those of natural origin (Kabata-Pendias \& Mukherjee, 2007; Alloway, 2013).

Elements present in soils can be associated with several reactive components. Although total element concentrations may indicate the overall level of elements in soils, they provide no information regarding the chemical nature or potential mobility and bioavailability of a particular element (Vijver et al., 2004; Jin et al., 2005; Powell et al., 2005). Sequential fractionation is a frequently used approach to evaluate element distribution 
into different chemical forms present in a solid phase. Conceptually, sequential fractionation categorizes elements associated with chemically homogeneous fractions that, ultimately, affect element availability (Clemente et al, 2008; Nobuntou et al, 2010; Burt et al, 2011; Cornejo-Ponce \& Acarapi-Cartes, 2011). Although often criticized due to lack of specificity of extractants and possible readsorption of elements during extraction (Rao et al., 2008). Sequential fractionation can provide useful information to predict the fate of heavy metal in the environment (Michalke, 2003; Michalke, 2009; Ajmone-Marson \& Biasioli, 2010; Nannoni et al, 2011; Luo et al, 2012).

The mobility of heavy metals in soil samples can be evaluated by dividing the fractions that are weakly bound to soil components with all fractions (Kabala \& Singh 2001). These are usually classified according to a risk assessment code (RAC) based on the strength of the bond between the element and the different geochemical fractions in soils and the ability of the elements to be released and enter into the food chain (Rodriguez et al, 2010). The RAC expressed as a percentage, is defined by taking the ratio of the mobile fractions (water soluble and exchangeable fractions) to the total concentration of elements in the soil. However, Batjargal et al (2010) has expressed that exchangeable and carbonate bound fractions are bioavailable and additionally, fraction bound to $\mathrm{Fe} / \mathrm{Mn}$ oxides could be leached by weak acidic solution. Consequently, it is therefore necessary to assess the possible contribution of these potentially leachable pools of elements to bioavailable component and thus ascertain their risk in the environment.

Generally, the extent of anthropogenic contamination can be expressed using the enrichment index and it has been widely used by several authors in order to establish the degree of contamination by elements (Rubio et al., 2000; Loska et al., 2003; Ghrefat et al., 2011; Ahiamadjie et al., 2011; Likuku et al., 2013). This index is usually computed by averaging the ratios of the concentrations of the measured element to the hazard criteria or to the soil quality guidelines for that element. It is notable that neither in Nigeria nor sub-Saharan Africa have soil quality guidelines been established. Thus, the determination of permissible levels of element concentration in soil and the application of such standards as used by other countries may not be easy as there could be varying lithography. Hence rather than expressing the enrichment index (equation 1) as an estimate of pollution, it can as well be used as an estimate of possible anthropogenic influences on the surface environment assuming that under normal conditions pedogenic process on the subsurface soil should give rise to surface soil.

$$
T F i=(X i / X r e f) /(\text { Yi } / \text { Yref })
$$

where, $\mathrm{Xi}$ is concentration of the metal in bulk soil in surface environment, Xref is the concentration of the Ti in bulk soil in surface environment, $\mathrm{Yi}$ is the concentration of metal in subsurface environment", Yref is the concentration of the Ti in subsurface environment. Values $>1.0$ indicate accumulation of metals in soils due to anthropogenic sources while values of 1.0 and $<1.0$ show that enrichment of metals is not detectable and loss of metals due to pedogenic processes (Acosta et al, 2011).

\section{Materials and Methods}

\subsection{Sampling Description}

Southern part of Ondo State lying between $6^{\circ} 15^{\prime} \mathrm{N}-5^{\circ} 10^{\prime} \mathrm{E}$ and $7^{\circ} 00^{\prime} \mathrm{N}-4^{\circ} 20^{\prime} \mathrm{E}$, wherein lies the bitumen belt, was divided into regular grids of $12.5 \times 12 \mathrm{sq} . \mathrm{Km}$ and in each of the grid, five points were sampled and pooled to represent a field composite sample (Figure 1). All samples were georeferenced using Geographic Positioning System (GPS). Each sample was air dried in the open laboratory, picked, disaggregated using mortar and pestle, sieved through $2 \mathrm{~mm}$ nylon mesh (British Standard) and stored in poly propylene bottles prior to analysis (Patnaick, 2004). 


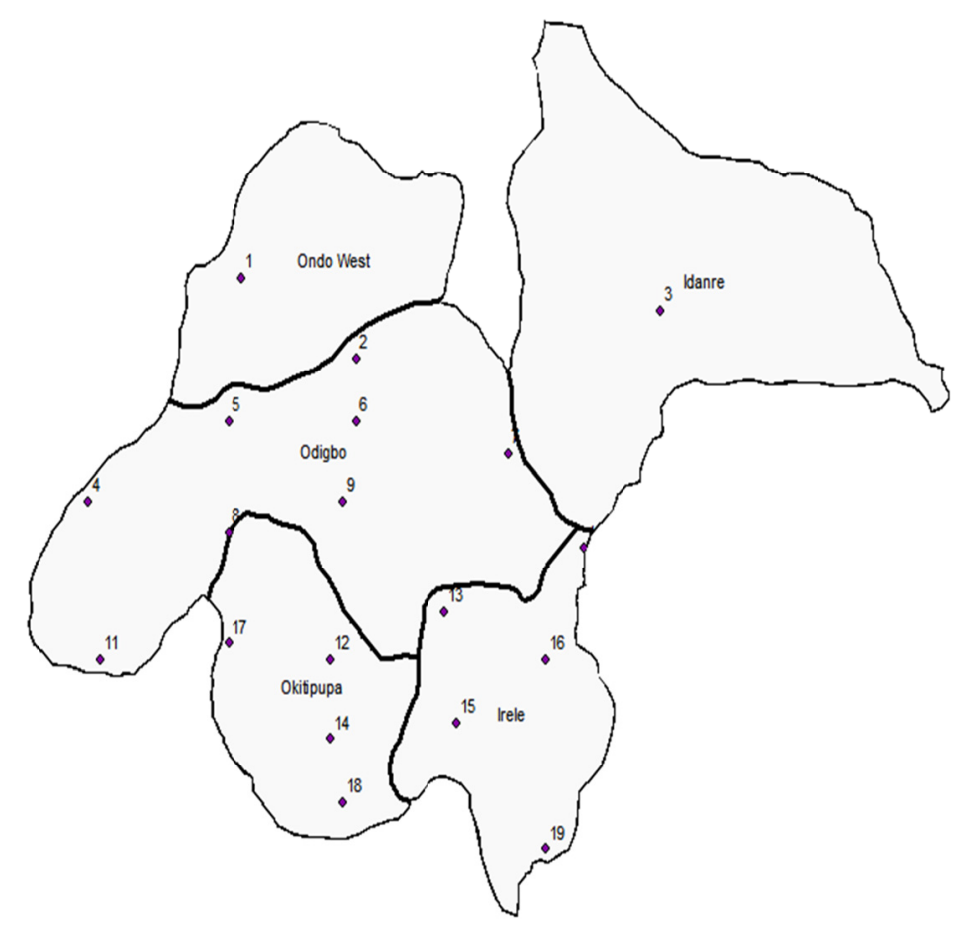

Figure 1. Map showing the geographically referenced sampling points

\subsection{Determination of Total Fe, Zn, Cu and Mn Contents of Soil}

$200 \mathrm{mg}$ of air dried soil sample was weighed into an acid washed Teflon beaker and placed on a sand bath with mixtures of the following acids; $10 \mathrm{ml} \mathrm{HF}+5 \mathrm{ml} \mathrm{HClO}{ }_{4}+2.5 \mathrm{ml} \mathrm{HCl}+2.5 \mathrm{ml} \mathrm{HNO}_{3}$. The mixture was heated to almost dryness to dissolve the silica content of the soil sample. The resulting salt was dissolved in $20 \%$ aqua regia $\left(\mathrm{HCl}: \mathrm{HNO}_{3} / 1: 3\right)$, filtered and made up to $10 \mathrm{ml}$ in a standard volumetric flask (Zhang et al, 2008). Each digest was analysed using inductively coupled plasma-optical emission spectrophotometer (ICP-OES).

\subsection{Selective Extraction Procedure}

The following sequential extraction procedure was applied to $10 \mathrm{~g}$ soil:

Stage 1: Soluble + Exchangeable: $10 \mathrm{~g}$ of air dried soil sample was leached at room temperature for $2 \mathrm{~h}$ with 40 $\mathrm{ml}$ of $1 \mathrm{M} \mathrm{MgCl}_{2}(\mathrm{pH}=5)$ with continuous agitation,

Stage 2: Bound to Organic Matter: residue from stage 1 above was leached at room temperature with $30 \mathrm{ml}$ $0.5 \mathrm{M} \mathrm{NaOH}$ and agitated continuously for $16 \mathrm{~h}$,

Stage 3: Precipitation of Carbonates: to the residue from stage 2 above was added $30 \mathrm{ml}$ of $0.05 \mathrm{MNa}_{2} \mathrm{EDTA}$ will be used to leach it at room temperature for $6 \mathrm{~h}$,

Stage 4: Bound to Iron and Manganese: the residue from stage 3 above was extracted in darkness at room temperature for $4 \mathrm{~h}$ with $30 \mathrm{ml}$ Oxalic acid-Oxalate, $\mathrm{pH} 3.0$,

Stage 5: Precipitation of Sulphides: the residue from stage 4 above was digested with $50 \mathrm{ml} 4 \mathrm{M} \mathrm{HNO}_{3}$ and the mixture heated on sand bath to $80 \pm 2^{\circ} \mathrm{C}$ for $16 \mathrm{~h}$ with occasional agitation,

Stage 6: Residue: Obtained by difference between the total content and the sum of the above five fractions (Figure 2).

Selective extractions were carried out in $50 \mathrm{ml}$ polypropylene centrifuge tubes with caps to minimize losses of solid material. Between each successive extraction, separation was performed by centrifuging at $6000 \mathrm{rpm}$ for 25 minutes. The resultant supernatant solution was decanted, filtered and made up to volume in a $50 \mathrm{ml}$ standard flask with distilled water. This solution was analysed for multi-elements while the next extractant was added the residue sample (Gimeno-Garcia et al, 1995). Between each step in the sequence, the residue was not washed with distilled water because washing may results in elements losses and therefore low recoveries of elements in a 
given extraction step. To reduce the possible error, the equation suggested by Sposito et al (1982) was applied. This equation contains a correction for the amount of element in the solution entrained with the soil sample after the centrifugation that follows each extraction:

$$
\text { ugextracted }=(C x M)-\left(C^{\prime} x M^{\prime}\right)
$$

Where $\mathrm{C}$ is the concentration $(\mu \mathrm{g} / \mathrm{g})$ of element in the extracted solution, $C^{\prime}$ is the concentration $(\mu \mathrm{g} / \mathrm{g})$ of element in the solution extracted in the preceding step of the sequence, $\mathrm{M}$ is the mass $(g)$ of extractant used, $M^{\prime}$ is the mass $(g)$ of solution carried over to the present extraction from the preceding one. Extracts were analysed using inductively coupled plasma-optical emission spectrophotometer (ICP-OES).

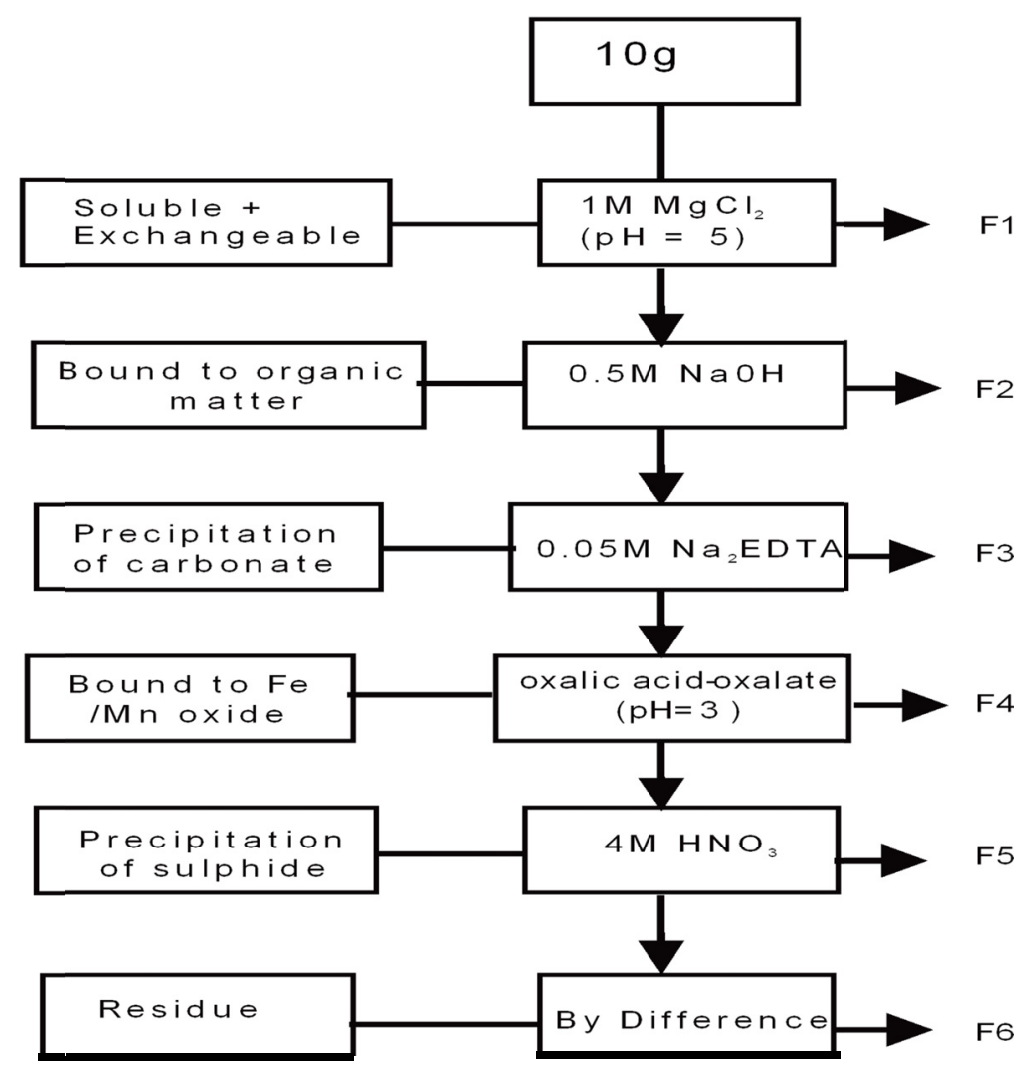

Figure 2. Flow chat for the sequential extraction procedure

\section{Results and Discussion}

\subsection{Spatial Distribution of $\mathrm{Cu}, \mathrm{Fe}, \mathrm{Mn}$ and $\mathrm{Zn}$}

The surface environment have lower $\mathrm{Cu}$ concentrations in the NE through the centre towards the $\mathrm{S}$ axes of the study area while higher concentration was found along the $\mathrm{E}$ and $\mathrm{NW}, \mathrm{W}$ and $\mathrm{SW}$ axes (Figure 3). Total $\mathrm{Cu}$ spatial distribution in the subsurface environment is similar to those of the surface environment (Figure 4). Consequently, it can be said that the same factor could be responsible for total $\mathrm{Cu}$ distribution in both the surface and subsurface environment. However, copper is higher in concentration in the surface than the subsurface environment. Spatial distribution map of total Fe concentration in both surface (Figure 5) and subsurface (Figure 6) environment indicated that higher total $\mathrm{Fe}$ concentration was found in the $\mathrm{N}$ while lower concentration was obtained in the $\mathrm{S}$. This demarcation correlate with bedrock type; the $\mathrm{N}$ is of basement complex while the $\mathrm{S}$ is undifferentiated essentially sedimentary. The total Mn concentration spatial distribution map for surface environment shows that higher concentration of Mn were found in the $\mathrm{N}$ with NW having the highest while lower concentration spread to the S (Figure 7). Total Mn concentrations spatial distribution of subsurface is similar to that of surface environment in all respect with the subsurface environment having higher values of $\mathrm{Mn}$ concentration than the surface environment (Figure 8). Total $\mathrm{Zn}$ concentration in the surface environment is relatively higher from the $\mathrm{N}$ central through the centre of the study area to the $\mathrm{S}$ with highest concentration in the E (Figure 9). The spatial distribution of total $\mathrm{Zn}$ concentration in the subsurface environment is similar to the surface environment though higher values were obtained in the case of subsurface environment (Figure 10). 


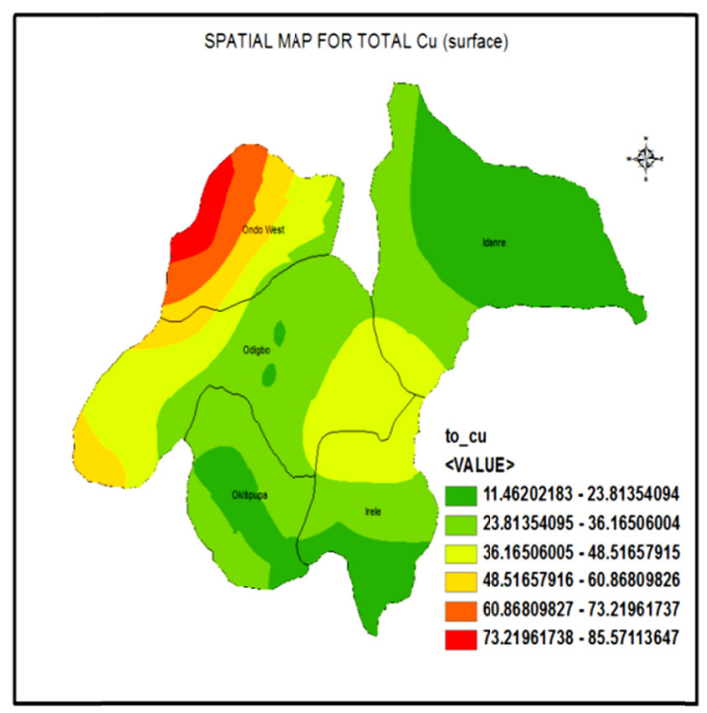

Figure 3. Spatial distribution map of total copper for surface soil

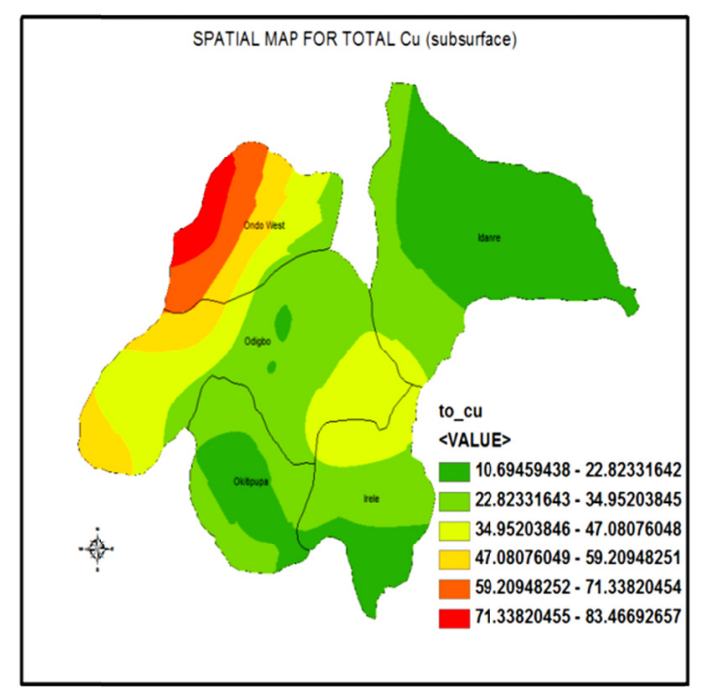

Figure 4. Spatial distribution map of total copper for subsurface soil 


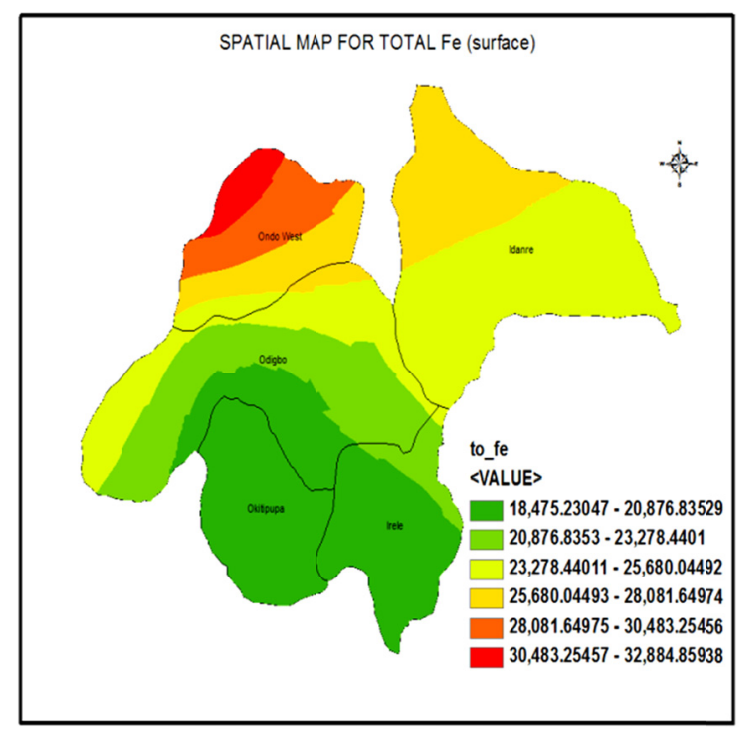

Figure 5. Spatial distribution map of total iron for surface soil

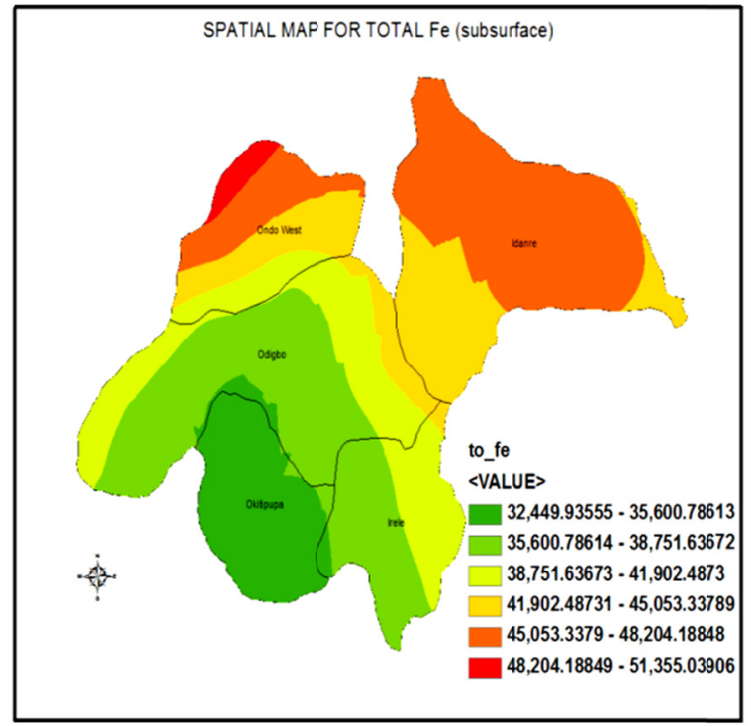

Figure 6. Spatial distribution map of total iron for subsurface soil 


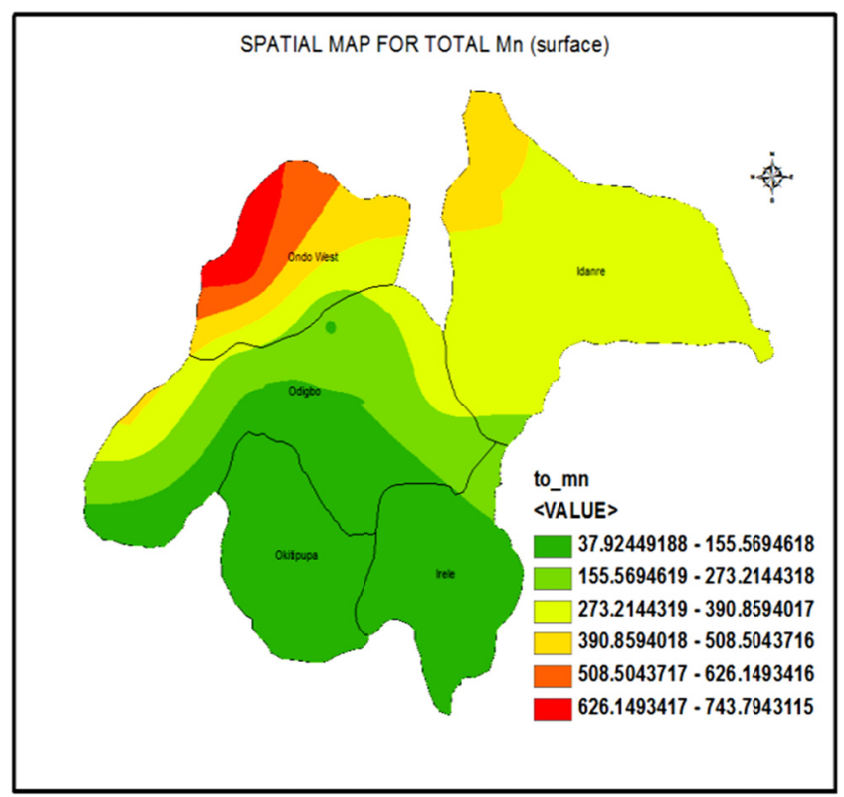

Figure 7. Spatial distribution map of total manganese for surface soil

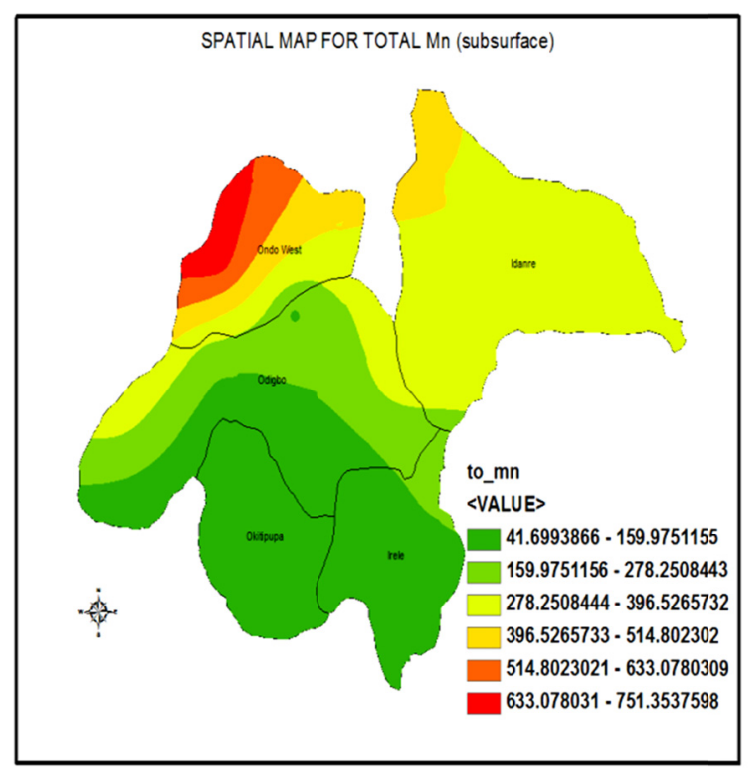

Figure 8. Spatial distribution map of total manganese for subsurface soil 


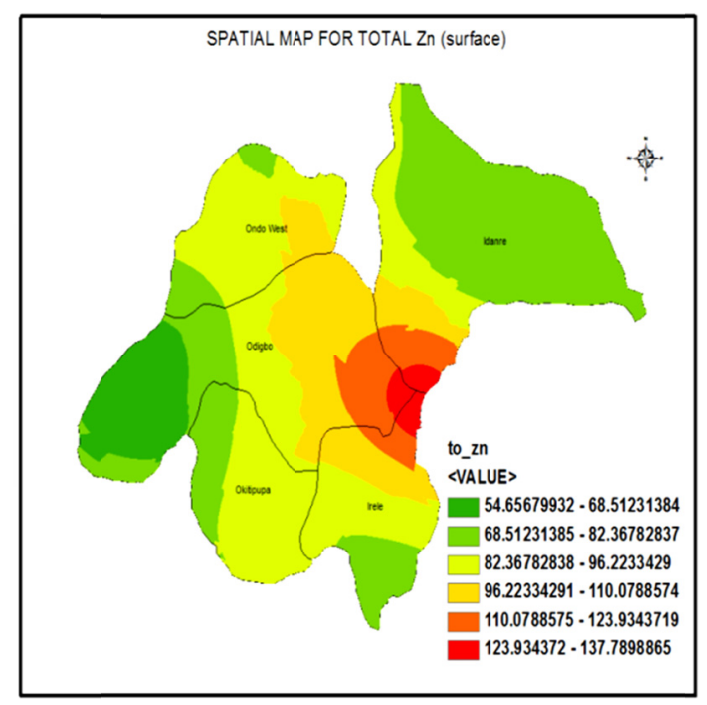

Figure 9. Spatial distribution map of total zinc for surface soil

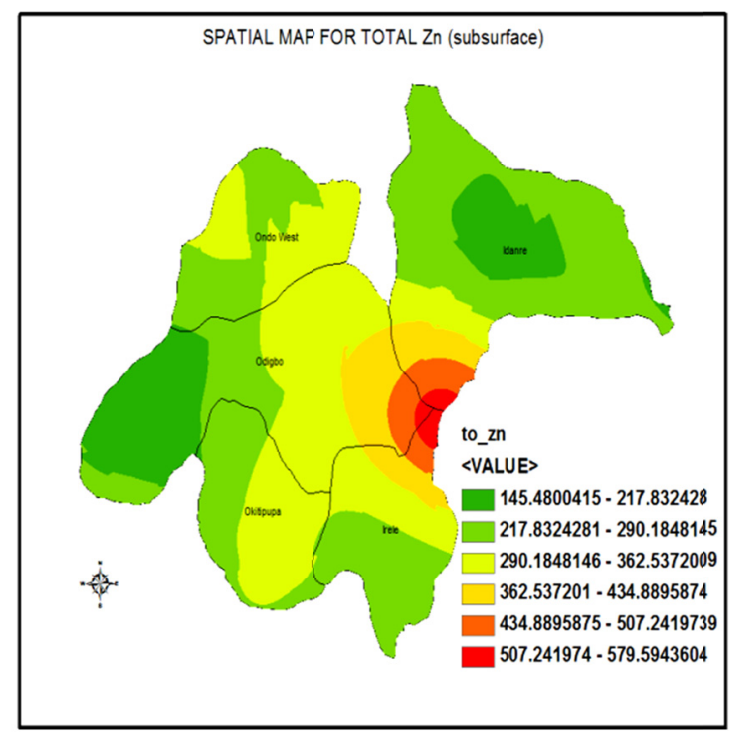

Figure 10. Spatial distribution map of total zinc for subsurface soil

\subsection{Bioavailability of $\mathrm{Cu}, \mathrm{Fe}, \mathrm{Mn}$ and $\mathrm{Zn}$ from the Soil Matrix}

The results for the selective extraction of the trace elements are shown in Table 3 below:

According to Ma \& Rao (1997) assuming that bioavailability is related to solubility, metal bioavailability should decrease in the order:

\section{Exchangeable $>$ Carbonate $>$ Fe-Mn oxide $>$ Organic $>$ Sulphide $>$ Residual}

Thus metals in the non-residual fractions are more bioavailable than in residual fraction. It can be said that nonresidual fractions in the present study for the metals $(\mathrm{Cu}, \mathrm{Mn}, \mathrm{Zn})$ were greater than the residual fractions except $\mathrm{Fe}$ in the surface soil environment while residual fractions for metals (Fe, $\mathrm{Mn}, \mathrm{Zn}$ ) were greater than non residual fractions in the subsurface environment except $\mathrm{Cu}$. Hence, $\mathrm{Cu}, \mathrm{Mn}$ and $\mathrm{Zn}$ seem to be more mobile in 
surface environment while only $\mathrm{Cu}$ is therefore potentially mobile in subsurface soil environment. This could be tantamount to their bioavailability considering the conclusion of Ma \& Rao (1997). Rastmanesh et al., (2010) has expressed that residual fraction constitutes a significant proportion for all elements.

Table 3. Percent phase fractionation of trace elements in surface and subsurface soil environment

\begin{tabular}{ccccccccc}
\hline & Co $\%$ & Fe $\%$ & Mn $\%$ & Zn $\%$ & Cu \% & Fe \% & Mn \% & Zn \% \\
\hline \multicolumn{7}{c}{ Surface Soil } \\
\hline F1 & 1.63 & 0.31 & 3.03 & 2.63 & 3.33 & 0.34 & 1.04 & 2.88 \\
F2 & 10.33 & 0.32 & 13.56 & 6.25 & 15.70 & 0.31 & 6.30 & 6.42 \\
F3 & 7.61 & 3.55 & 6.49 & 13.51 & 13.65 & 1.68 & 7.27 & 6.35 \\
F4 & 25.27 & 6.91 & 14.00 & 12.91 & 13.37 & 4.31 & 10.94 & 8.70 \\
F5 & 13.24 & 19.27 & 16.82 & 18.92 & 8.23 & 18.38 & 12.28 & 15.18 \\
F6 & 41.91 & 69.63 & 46.10 & 45.79 & 45.72 & 75.00 & 62.16 & 60.47 \\
\hline F1-Soluble+Exchangeables; F2-Organically & Bound; $\quad$ F3-Carbonate & Bound; F4-Fe/Mn & Oxides & Bound; \\
F5-Sulphide Bound; F6-Residue & & & & & &
\end{tabular}

According to Kaasalainen \& Yli-Halla (2003), the proportion of the residual fraction reflects native metal concentration in soil. Consequently, the metal Fe in the surface and Fe, Mn, $\mathrm{Zn}$ in the subsurface environment of the southern part of Ondo State, Nigeria were not potentially bioavailable and they constitute probably the native concentrations in soil of the area under study. There was similar observation in the work of Agbaire \& Akporhonor (2014) but the view of Aikpokpodion et al. $(2012,2013)$ differs. Generally, the metals in the surface environment were more bioavailable than subsurface environment considering the relative larger value of residual fractions of the latter. Water soluble + Exchangeables were very low in all metals and within the surface and subsurface environment. Percentage of metals that are acid leachable or oxidisable were very high and a change in these conditions would increase the bioavailable metals in the two environment. The order is as follows for metals in surface and subsurface environment:

Surface: Cu, F6 $>$ F2 $>$ F3 $>$ F4 $>$ F5 $>$ F1; Fe, F6 $>$ F5 $>$ F4 $>$ F3 $>$ F2 $>$ F1; Mn, F6 $>$ F5 $>$ F4 $>$ F2 $>$ F3 $>$ F1; Zn, $\mathrm{F} 6>\mathrm{F} 5>\mathrm{F} 3>\mathrm{F} 4>\mathrm{F} 2>\mathrm{F} 1$

Subsurface: $\quad \mathrm{Cu}, \mathrm{F} 6>\mathrm{F} 2>\mathrm{F} 3>\mathrm{F} 4>\mathrm{F} 5>\mathrm{F} 1 ; \quad$ Fe, F6 $>$ F5 $>$ F4 $>$ F3 $>$ F1 $>$ F2; $\quad$ Mn, $\mathrm{F} 6>\mathrm{F} 5>\mathrm{F} 2>\mathrm{F} 2>\mathrm{F} 3>\mathrm{F} 1 ; \quad$ Zn, F6 $>$ F5 $>$ F4 $>$ F2 $>$ F3 $>$ F 1

\subsection{Mobility of $\mathrm{Cu}, \mathrm{Fe}, \mathrm{Mn}$ and $\mathrm{Zn}$ from the Soil Matrix}

Three mobility factors were defined thus: (i) soluble+exchangeable, (ii) soluble+exchangeable + carbonates and (iii) soluble+exchangeable + carbonates + bound to Fe/Mn oxides to total concentrations of the element in the soil. According to Rodriguez et al (2009), there may be no risk when these fractions represent lower than $1 \%$ of the total concentrations, low risk for $1-10 \%$, medium risk for $11-30 \%$, a high risk for $30-50 \%$ and a very high risk for higher percentages. All the metals in this study were more mobile in the surface than the subsurface environment (Figures 11-14). Considering the mobility factor in terms of relative percent of soluble + exchangeables for the elements shows that Fe was with no risk at both surface and subsurface environment while $\mathrm{Cu}, \mathrm{Mn}$ and $\mathrm{Zn}$ were with low risk. However, Fe was with low risk at both surface and subsurface environment; $\mathrm{Cu}$ was associated with medium risk in both environments, Mn was with low risk in the surface and medium risk in the subsurface; $\mathrm{Zn}$ was associated with medium risk in the surface and low risk in the subsurface when the relative percent of soluble + exchangeables + carbonate were considered. Moreover, the relative percent of soluble + exchangeables ${ }_{+}$carbonate $+\mathrm{Fe} / \mathrm{Mn}$ oxides indicated that $\mathrm{Cu}$ was with high risk in both surface and subsurface environment; Fe was with low risk in both; Mn was with medium risk in both while $\mathrm{Zn}$ was with high risk in the surface and medium risk in the subsurface. The mobility of $\mathrm{Cu}, \mathrm{Fe}, \mathrm{Mn}$ and $\mathrm{Zn}$ increases progressively with severity of prevailing conditions. However, the progressive increase in the risk of $\mathrm{Cu}$ from low risk through medium risk to high risk in both surface and subsurface environment and similarly that of $\mathrm{Zn}$ in surface environment is noteworthy. 

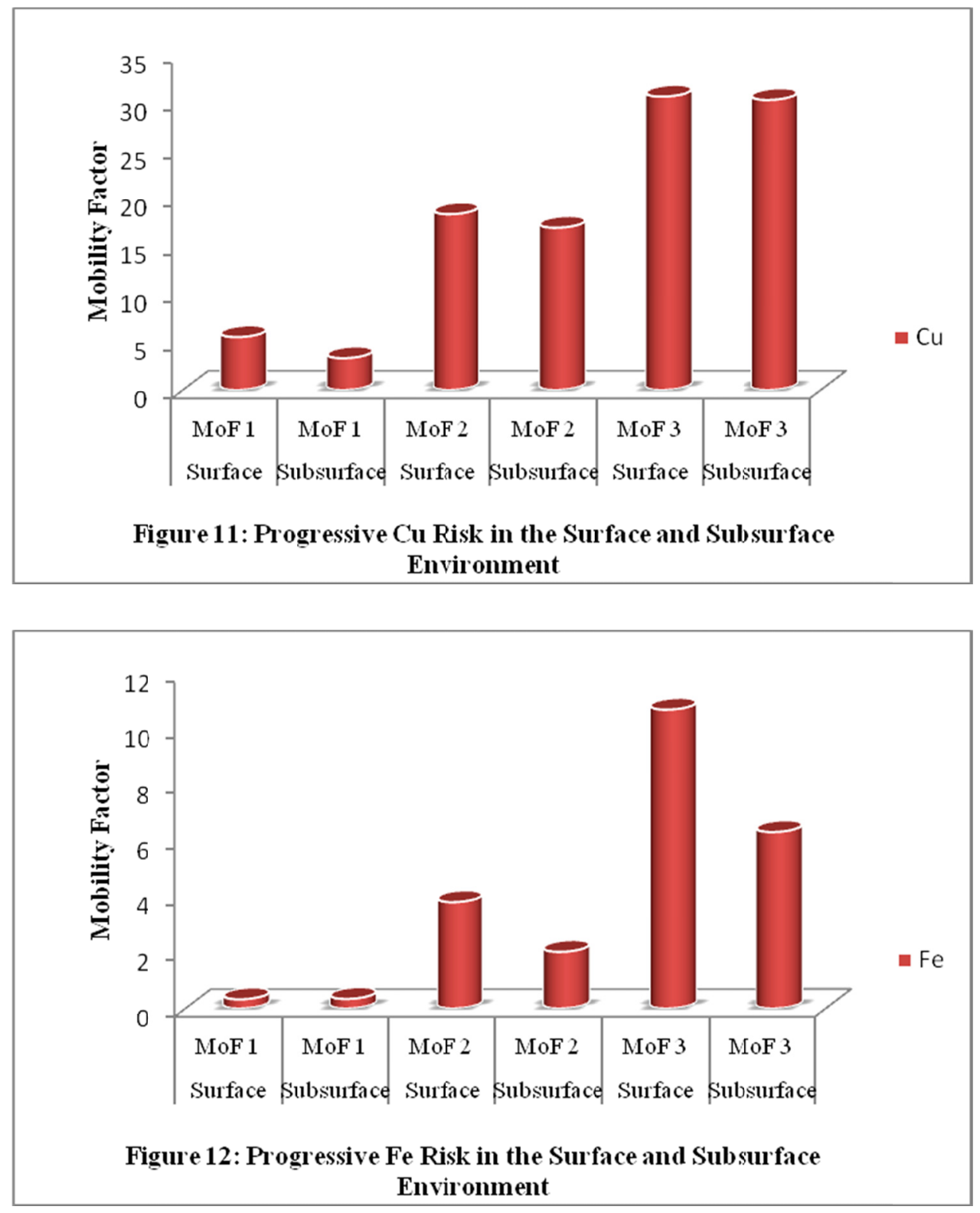

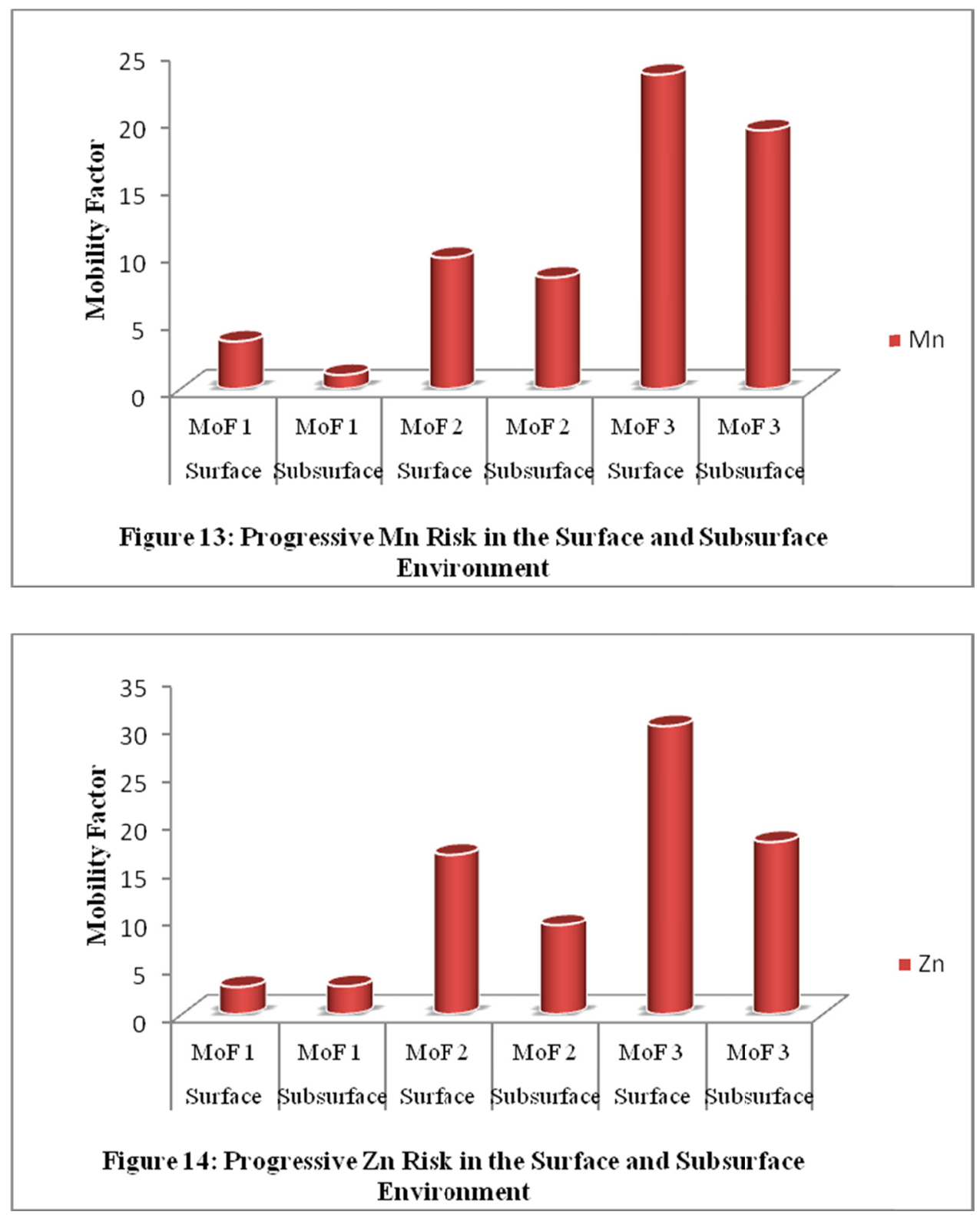

\subsection{Assessment of Possible Sources of $\mathrm{Cu}, \mathrm{Fe}, \mathrm{Mn}$ and $\mathrm{Zn}$ in the Surface Environment}

Surface soil metal concentrations are a product of a variety of natural and anthropogenic sources. It has been said, however, that rural, non-highly agricultural areas should not be assumed to have low soil metal concentrations (Davis et al., 2009) indicative of non anthropogenic sources. The results indicated that $\mathrm{Cu}$ and $\mathrm{Mn}$ might be associated with anthropogenic sources with their values higher than 1 while $\mathrm{Fe}$ and $\mathrm{Zn}$ might have been lost during pedogenic processes since their value was less than 1 (Table 4). Davis et al, (2009) have earlier expressed that some metals like Mn were consistently associated with natural sources in both the rural and the urban areas while metal like $\mathrm{Cu}$ was associated with both natural and anthropogenic sources. Their observation about $\mathrm{Cu}$ was found to be the same with this study but that of Mn was not. Kabala \& Singh (2001) also found $\mathrm{Cu}$ to be associated with contamination and anthropogenic sources. For some metals associated with anthropogenic inputs, land use and the density of industrial facilities appeared to play a role in the higher concentrations measured and their mobility, e.g. application of copper based fungicides and other similar chemicals could be attributed to $\mathrm{Cu}$ behavior in this study. 
Table 4. Assessment of sources of $\mathrm{Cu}, \mathrm{Fe}, \mathrm{Mn}$ and $\mathrm{Zn}$ in surface environment with $\mathrm{Ti}$ as normalizer

\begin{tabular}{ccccc}
\hline & Elements Average & Min & Max & \\
\hline $\mathrm{Cu}$ & 1.22 & & 0.92 & 1.57 \\
$\mathrm{Fe}$ & 0.66 & & 0.46 & 1 \\
$\mathrm{Mn}$ & 1.11 & & 0.81 & 1.53 \\
$\mathrm{Zn}$ & 0.35 & & 0.27 & 0.45 \\
\hline
\end{tabular}

\section{Conclusion}

Total trace metal composition of soils are of little importance in determining the total trace metal uptake by plants and consequent level of risk these elements may pose to plants and the food chain. This is because different binding forms have different mobilities, bioavailabilities and potential environmental threat. Forest areas can be prone to trace element changes when industrial and mining activities are introduced and the consequences of bioaccumulation of these elements are obvious. Southern Ondo State is prone to future industrial and bitumen exploitations and there is need to document the industrial and mining pre activities. This studies has therefore indicated that $\mathrm{Cu}$ and probably $\mathrm{Zn}$ could be very mobile in this environment and may pose some level of risk to ecosystem and underground water aquifers. This risk may be greater than predicted as future industrial and mining activities may increase the total concentration load of the metals and also may have negative impact on the soil physicochemical properties most especially soil acidity. This will increase the portion that may be soluble, exchangeable and bound to carbonate including oxidisable or reducible.

\section{Acknowledgement}

The authors wish to acknowledge the assistance of Dr. Babajide Jelili of the Department of Chemistry, Environmental and Nano Science Unit, University of Western Cape, South Africa for the use of ICP-OES chemical instrumentation and analyses of some samples. The assistance of Dr. Yusuff Tajudeen of Mathematical Sciences Department, Federal University of Technology, Akure is also appreciated for his facilitating role during the analysis. Prof Boluda R. of Department of Desertification, Institute de Agroguimica y Tecnologia de Alimentos (IATA-CSIC), Spain is appreciated for providing the authors with their research paper upon which the selective extraction was based.

\section{References}

Acosta, J. A., Martinez-Martinez, S., \& Arocena, A. F. (2011). Accumulators of Major and Trace Elements in Particle Size Fraction of Soils on Eight Different Parent Materials. Geoderma, 161, 30-42. http://dx.doi.org/10.1016/j.geoderma.2010.12.001

Agbaire, P. O., \& Akporhonor, E. E. (2014). Heavy Metal Determination by Sequential Extraction in Agricultural Farmland Soils in Selected Farms in Abraka, Delta State, Nigeria. IOSR Journal of Environmental Science, Toxicology and Food Technology, 8(6-2), 47-55.

Ahiamadjie, H., Adukpo, O. K., Tandoh, J. B., Gyampo, O., Nyarku, M., MumuniI, I., Agyemang, O., Ackah, M., Otoo, F., \& Dampare, S. B. (2011). Determination of the Elemental Contents in Soils around Diamond Cement Factory, Aflao. Research Journal of Environmental and Earth Sciences, 3(1), 46-50.

Aikpokpodion, P. E., Lajide, L., \& Aiyesanmi, A. F. (2012). Metal Fractionation in Soils Collected from Selected Cocoa Plantations in Ogun State, Nigeria. World Journal of Agricultural Sciences, 20(5), 628-636.

Aikpokpodion, P. E., Lajide, L., \& Aiyesanmi, A. F. (2013). Characterization of Heavy Metal Fractions in Agrizcultural Soils Using Sequential Extraction Technique. World Journal of Agricultural Sciences, 9(1), 45-52.

Ajmone-Marsan, F., \& Biasioli, M. (2010). Trace Elements in Soils of Urban Areas. Water Air and Soil Pollution, 213, 121-143. http://dx.doi.org/10.1007/s11270-010-0372-6

Alloway, B. J. (2013). Heavy Metals in Soil: Trace Metals and Metalloids in Soil and Their Bioavailability. Springer Environmental Pollution Series, Springer Science + Business Media, Dordrecht, 613pp.

Batjargal, T., Otgonjargal, E., Baek, K., \& Yang, J-S. (2010). Assessment of Metals Contamination of Soils in Ulaanbaatar, Mongolia. Journal of Hazardous Materials, 184, 872-876. http://dx.doi.org/10.1016/j.jhazmat.2010.08.106

Bisi-Johnson, M. A., Obi, C. L., \& Ekosse, G. E. (2010). Microbiological and Health Related Perspectives of 
Geophagia: An Overview. African Journal of Biotechnology, 9(19), 5784-5791.

Blum, W. E. H., Warkentin, B. P., \& Frossard, E. (2006). Soil, Human Society and the Environment. In E. Frossard, W. E. H. Blum, \& B. P. Warkentin (Eds.), Function of Soils for Human Societies and the Environment, Geological Society (pp. 1-8). London Special publications, 266. http://dx.doi.org/10.1144/gsl.sp.2006.266.01.01

Burt, R., Weber, T., Park, S., Yochum, S., \& Ferguson, R. (2011). Trace Element Concentration and Speciation in Selected Mining-Contaminated Soils and Water in Willow Creek Flood Plain, Colorado. Applied and Environmental Soil Science, ID-237071, 20pp. http://dx.doi.org/10.1155/2011/237071

Clemente, R., Dickinson, N. M., \& Lepp, N. W. (2008). Mobility of Metal and Metalloids in a Multi-Element Contaminated Soil 20 Years after Cessation of the Pollution Source Activity. Environmental Pollution, 155, 254-261. http://dx.doi.org/10.1016/j.envpol.2007.11.024

Cornejo-Ponce, L., \& Acarapi-Cartes, J. (2011). Fractionation and Bioavailability of Arsenic in Agricultural Soils: Solvent Extraction Tests and Their Relevance in Risk Assessment. Journal of Environmental Science and Health, Part A., 46, 1247-1258. http://dx.doi.org/10.1080/10934529.2011.598807

Davis, H. T., Aelion, C. M., McDermott, S., \& Lawson, A. B. (2009). Identifying Natural and Anthropogenic Sources of Metals in Urban and Rural Soils using GIS-based data, PCA, and Spatial interpolation. Environmental Pollution, 157(8-9), 2378-2385. http://dx.doi.org/10.1016/j.envpol.2009.03.021

Ghrefat, H. A., Abu-Rukah, Y., \& Rosen, M. A. (2011). Application of Geoaccumulation Index and Enrichment Factor for Assessing Metal Contamination in the Sediments of Kafrain Dam, Jordan. Environmental Monitoring and Assessessment., 178(1-4), 95-109. http://dx.doi.org/10.1007/s10661-010-1675-1

Gimeno- Grarcia, E., Andreu, V., \& Boluda, R. (1995). Distribution of Heavy Metals In Rice Farming Soils. Archival of Environmental Contamination and Toxicology, 29, 476-483. http://dx.doi.org/10.1007/bf00208377

Gruhn, P., Goletti, F., \& Yudelman, M. (2003). Integrated Nutrient Management, Soil Fertility and Sustainable Agriculture. Current Issues and Future Challenges. Food, Agriculture and the Environment Discussion Paper 32, International Food Policy Research Institute, Washington, D.C., U.S.A, 38PP.

Jin, C. W., Zheng, S. J., He, Y. F., Zhou, G. D., \& Zhou, Z. X. (2005). Lead Contamination in Tea Garden Soils and Factors Affecting its Bioavailability. Chemosphere, 59, 1151-1159. http://dx.doi.org/10.1016/j.chemosphere.2004.11.058

Kaasalainen, M., \& Yli-Halla, M. (2003). Use of sequential extraction to assess metal partitioning in soils. Environmental Pollution, 126, 225-233. http://dx.doi.org/10.1016/S0269-7491(03)00191-X

Kabala, C., \& Singh, B. R. (2001). Fractionation and Mobility of Copper, Lead and Zinc in Soil Profiles in the Vicinity of a Copper Smelter. Journal of Environmental Quality, 20, 485-492. http://dx.doi.org/10.2134/jeq2001.302485x

Kabata-Pendias, A., \& Mukherjee, A. B. (2007). Trace Elements from Soil to Human. Springer, Berlin, Netherlands, 550pp. http://dx.doi.org/10.1007/978-3-540-32714-1

Likuku, A. S., Mmolawa, K. B., \& Gaboutloeloe, G. K. (2013). Assessment of Heavy Metal Enrichment and Degree of Contamination around the Copper-Nickel Mine in the Selebi Phikwe Region, Eastern Botswana. Environment and Ecology Research, 1(2), 32-40.

Loska, K., Wiechuła, D., Barska, B., Cebula, E., \& Chojnecka, A. (2003). Assessment of Arsenic Enrichment of Cultivated Soils in Southern Poland. Polish Journal of Environmental Studies, 12(2), 187-192.

Luo, X.-S., Yu, S., \& Li, X.-D. (2012). The Mobility, Bioavailability and Human Bioaccessibility of Trace Metals in Urban Soils of Hong Kong. Applied Geochemistry, 29, 995-1004. http://dx.doi.org/10.1016/j.apgeochem.2011.07.001

Ma, L. O., \& Rao, G. N. (1997). Heavy Metals in the Environment. Journal of Environmental Quality, 26, 259-264. http://dx.doi.org/10.2134/jeq1997.00472425002600010036x

Michalke, B. (2003). Element Speciation Definitions, Analytical Methodology and Some Examples. Ecotoxicology and Environmental Safety, 56, 122-139. http://dx.doi.org/10.1016/S0147-6513(03)00056-3

Michalke, B. (2009). Perspective of Element Speciation. Journal of Environmental Monitoring, 11, 1754-1756. http://dx.doi.org/10.1039/b915456f 
Mirsal, I. A. (2008). Soil Pollution: Origin, Monitoring and Remediation (2nd ed.). Springer Science + Business Media, Dordrecht, 312pp.

Nannoni, F., Protano, G., \& Riccobono, F. (2011). Fractionation and Geochemical Mobility of Heavy Elements in Soil of a Mining Area in Northern Kosovo. Geoderma, 161, 63-73. http://dx.doi.org/10.1016/j.geoderma.2010.12.008

Nobuntou, W., Parkpian, P., Tim-kim-Oanh, N., Noomhorm, A., Delaune, R. D., \& Jugsujinda, A. (2010). Lead Distribution and its Potential Risk to The Environment: Lesson Learned from Environmental Monitoring of Abandon Mine. Journal of Environmental Science and Health, Part A., 45, 1702-1714. http://dx.doi.org/10.1080/10934529.2010.513232

Patnaick, P. (2004). Dean's Analytical Chemistry Handbook (2nd ed.). McGraw Hill Companies, Inc, USA., $163 \mathrm{pp}$.

Powell, K. J., Brown, P. L., Byrne, R. H., Gajda, T., Hefter, G., Sjoberg, S., \& Wanner, H. (2005). Chemical

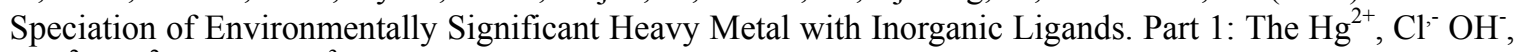
$\mathrm{CO}_{3}{ }^{2-} \mathrm{SO}_{4}{ }^{2-}$ and $\mathrm{PO}_{4}{ }^{3-}$ Aqueous Systems. Pure and Applied Chemistry, 77, 739-800. http://dx.doi.org/10.1351/pac200577040739

Rao, C. R. M., Sahuquillo, A., \& Lopez Sanchez, J. F. (2008). A review of the different methods applied in environmental geochemistry for single and sequential extraction of trace elements in soils and related materials. Water, Air and Soil Pollution, 189, 291-333. http://dx.doi.org/10.1007/s11270-007-9564-0

Rastmanesh, F., Moore, F., Kharrati-Kopaei, M., Keshavarzi, B., \& Behrouz, M. (2010) Heavy metal enrichment of soil in Sarcheshmeh copper complex. Environmental Earth Sciences, 62, 329-336. http://dx.doi.org/10.1007/s12665-010-0526-2

Retallack, G. J. (2001). Soils of the Past: An Introduction to Paleopedology (2nd ed.). Blackwell Science Ltd, Oxford, 404pp. http://dx.doi.org/10.1002/9780470698716

Rodrigues, S. M., Henriques, B., Coimbra, J., Ferreira da Silva, E., Pereira, M. E., \& Duarte, A. C. (2010). Water-soluble fraction of mercury, arsenic and other potentially toxic elements in highly contaminated sediments and soils. Chemosphere, 78, 1301-1312. http://dx.doi.org/10.1016/j.chemosphere.2010.01.012

Roivainen, P., Makkonen, S., Holopainen, T., \& Juutilainen, J. (2012). Elements Interaction and Soil Properties Affecting the Soil-to-Plant Transfer of Six Elements Relevant to Radioactive Waste in Boreal Forest. Radiation, Environment and Biophysics, 51(1), 69-78. http://dx.doi.org/10.1007/s00411-011-0393-6

Rubio, B., Nombela, M. A., \& Vilas, F. (2000). Geochemistry of Major and Trace Elements in Sediments of the Ria deVigo (NW Spain): an Assessment of Metal Pollution. Marine Pollution Bulletin, 40(11), 968-980. http://dx.doi.org/10.1016/S0025-326X(00)00039-4

Sposito, G., Lund, L. J., \& Chang, A. C. (1982). Trace metal chemistry in arid zone field soils amended with sewage sludge: I. Fractionation of $\mathrm{Ni}, \mathrm{Cu}, \mathrm{Zn}, \mathrm{Cd}$ and $\mathrm{Pb}$ in solid phases. Soil Science Society of American Journal, 46, 260-264. http://dx.doi.org/10.2136/sssaj1982.03615995004600020009x

Vijver, M. G., van Gestel, C. A. M., Lanno, R. P., van Straalen, N. M., \& Peijnenburg, W. J. G. M. (2004). Internal Metal Sequestration and its Ecotoxicological Relevance: A Review. Environmental Science and Technology, 38, 4705-4712. http://dx.doi.org/10.1021/es040354g

Zhang, H. H., Li, F. B., Wu, Z. F., Li, D. Q., Xu, D. R., \& Yuan, H. X. (2008). Baseline Concentrations and Spatial Distribution of Trace Metals in Surface Soils of Guangdong Province, China. Journal of Environmental Quality, 37, 1752-1760. http://dx.doi.org/10.2134/jeq2007.0531

Zhang, X. P., Deng, W., \& Yang, X. M. (2002). The Background Concentration of 13 Soil Trace Elements and their Relationship to Parent Materials and Vegetation in Xizang (Tibet) China. Journal of Asian Earth Sciences, 21, 167-174. http://dx.doi.org/10.1016/S1367-9120(02)00026-3

\section{Copyrights}

Copyright for this article is retained by the author(s), with first publication rights granted to the journal.

This is an open-access article distributed under the terms and conditions of the Creative Commons Attribution license (http://creativecommons.org/licenses/by/3.0/). 